\title{
The concept and methodical assumptions for the development of dynamically scaled aircraft model (passenger aircraft)
}

\author{
Aleksander Olejnik, Stanisław Kachel, Robert Rogólski and Jarosław Milczarczyk \\ Military University of Technology - Faculty of Mechatronics and Aerospace, Warsaw, Poland
}

\begin{abstract}
The article describes the concept of scaled model and its application in the process of real aircraft prototyping. Computer simulations of aerodynamic flows are commonly used in the design of aircraft. Numerous data on the characteristics of an airplane can be obtained using tunnel tests of geometry scaled models. To get complete information in extreme or unstable conditions, dynamically scaled models are tested. The scaled model is reduced model of the real airplane which has specific qualities similar to real aircraft qualities and these relations are strictly defined with characteristic similarity numbers (factors). The paper presents methodology for determining scale factors in relation to geometric, aerodynamic and structural properties (mass, stiffness) of the aircraft. The methodology was presented on the example of passenger aircraft (Tu-154M) model developed in Faculty of Mechatronics and Aerospace of the Military University of Technology (FMA MUT Warsaw, PL).
\end{abstract}

\section{The concept of dynamically scaled model and its application in aircraft prototyping process}

The basic aerodynamic characteristics of a newly-designed aircraft are obtained from tunnel tests of geometrically reduced model. In this way, not all maneuverability and stability features can be determined, especially in extreme or transient conditions. E.g. at very large attack angles, during gusts and during a spin. To obtain some reliable dynamic data of plane in full flight scope, the additional tests in extreme and unstable conditions should be conducted. For such tests besides real aircraft, the dynamically scaled models are used.

Tests of dynamically scaled models without any propulsion are carried out in wind tunnels and during free-fall flights after dropping from high altitudes (fig.1). Tests of dynamically scaled models equipped with propulsion devices are carried out with radio control transmission (fig.2).

There are many advantages of using scale models in comparison to real airplane tests. First of all costs and safety are important. Apart of that it is sensible to save the time of prototyping process. Tests of real aircraft are carried out at the final design stage, after the prototype has been made. Tests of models can be carried out at the stage of initial design (fig.3). Results obtained from such tests may give useful suggestions for changing the 
incorrectly chosen direction of prototyping. Finally due to tests of dynamic models flight billions of Euros may be saved, in case of passenger airplane.
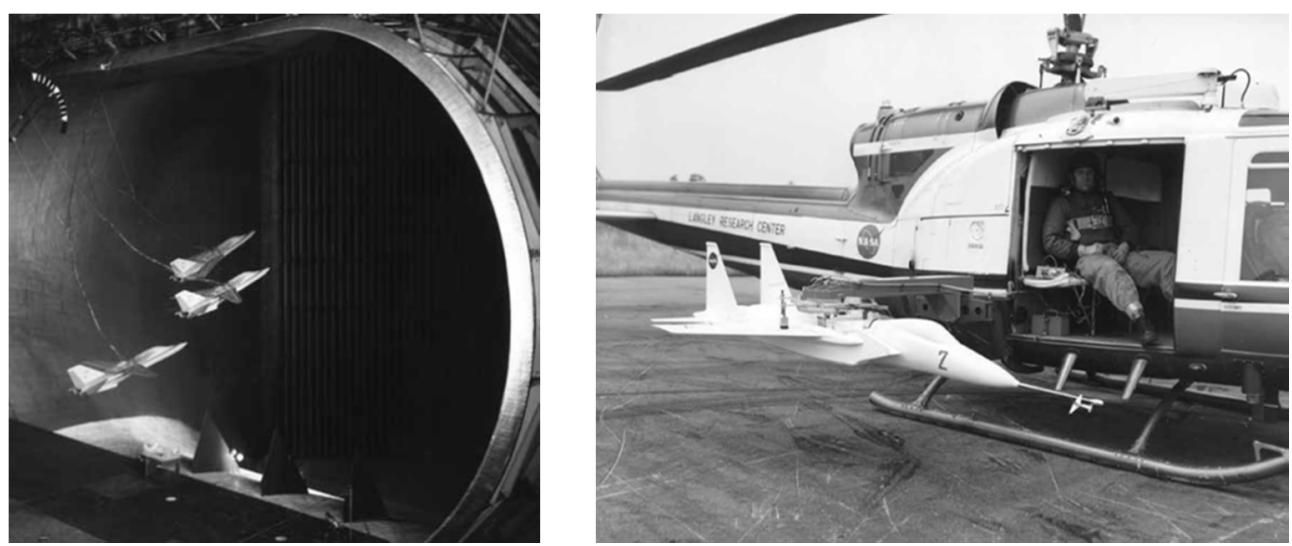

Fig. 1. Examples of NASA tests of dynamically scaled models without propulsion: a) in wind tunnel, and b) during free falls from high altitudes.

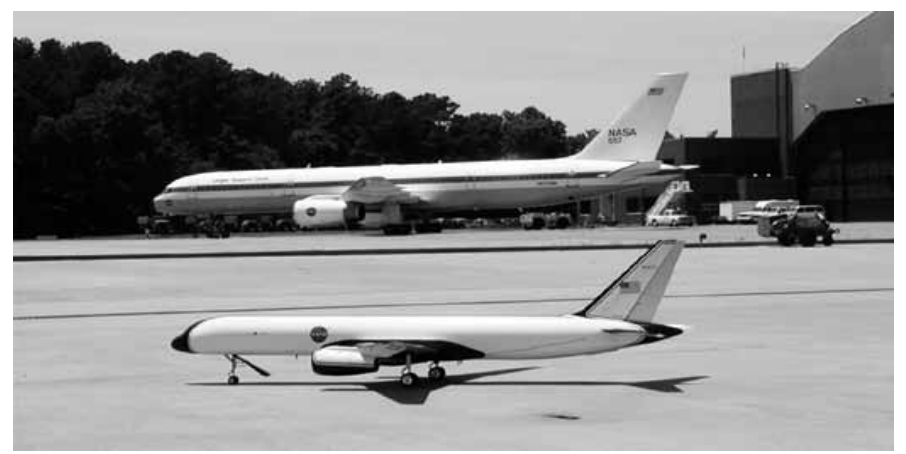

Fig. 2. B-757 - the dynamically scaled RC model (in scale 1:18) and the real aircraft, (NASA).

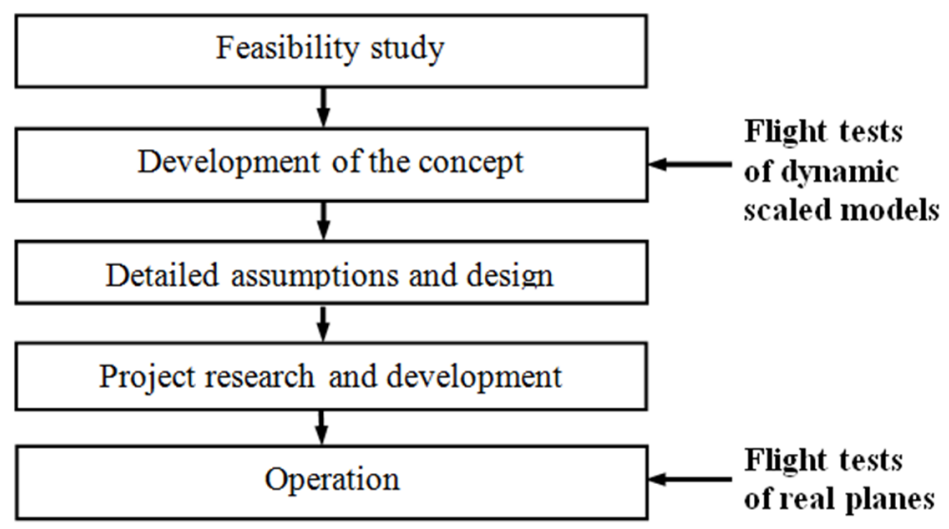

Fig. 3. Diagram of the design process including possible flight test operations:

1) scaled model testing - at the stage of initial design,

2) real aircraft testing - at the stage of capability verification of technology demonstrator or prototype acceptance. 


\section{Determination of scale factors in relation to geometric, aerodynamic and structural (mass, rigidity) properties}

To be dynamically similar, model has to have the solution of motion equations in dimensionless form the same as real airplane.

Assumption: the airplane is rigid and has 6 degrees of freedom.

Dynamic equations of motion for an airplane in a coordinate system related to a fixed pole:

$$
\begin{aligned}
& {\left[\begin{array}{cccccc}
m & 0 & 0 & 0 & S_{z} & -S_{y} \\
0 & m & 0 & -S_{z} & 0 & S_{x} \\
0 & 0 & m & S_{y} & -S_{x} & 0 \\
0 & -S_{z} & S_{y} & J_{x} & -J_{x y} & -J_{x z} \\
S_{z} & 0 & -S_{x} & -J_{y x} & J_{y} & -J_{y z} \\
-S_{y} & S_{x} & 0 & -J_{z x} & -J_{z y} & J_{z}
\end{array}\right]\left[\begin{array}{c}
\dot{\mathbf{U}} \\
\dot{\mathbf{V}} \\
\dot{\mathbf{W}} \\
\dot{\mathbf{P}} \\
\dot{\mathbf{Q}} \\
\dot{\mathbf{R}}
\end{array}\right]+\left[\begin{array}{rrrrrr}
\mathbf{0} & -\mathbf{R} & \mathbf{Q} & \mathbf{0} & \mathbf{0} & \mathbf{0} \\
\mathbf{R} & \mathbf{0} & -\mathbf{P} & \mathbf{0} & \mathbf{0} & \mathbf{0} \\
-\mathbf{Q} & \mathbf{P} & \mathbf{0} & \mathbf{0} & \mathbf{0} & \mathbf{0} \\
\mathbf{0} & -\mathbf{w} & \mathbf{v} & \mathbf{0} & -\mathbf{R} & \mathbf{Q} \\
\mathbf{w} & \mathbf{0} & -\mathbf{u} & \mathbf{R} & \mathbf{0} & -\mathbf{P} \\
-\mathbf{v} & \mathbf{u} & \mathbf{0} & -\mathbf{Q} & \mathbf{P} & \mathbf{0}
\end{array}\right] \times} \\
& \times\left[\begin{array}{cccrcc}
m & 0 & 0 & 0 & S_{z} & -S_{y} \\
0 & m & 0 & -S_{z} & 0 & S_{x} \\
0 & 0 & m & S_{y} & -S_{x} & 0 \\
0 & -S_{z} & S_{y} & J_{x} & -J_{x y} & -J_{x z} \\
S_{z} & 0 & -S_{x} & -J_{y x} & J_{y} & -J_{y z} \\
-S_{y} & S_{x} & 0 & -J_{z x} & -J_{z y} & J_{z}
\end{array}\right]\left[\begin{array}{c}
\mathbf{U} \\
\mathbf{V} \\
\mathbf{W} \\
\mathbf{P} \\
\mathbf{Q} \\
\mathbf{R}
\end{array}\right]=\left[\begin{array}{c}
\mathbf{X} \\
\mathbf{Y} \\
\mathbf{Z} \\
\mathbf{L} \\
\mathbf{M} \\
\mathbf{N}
\end{array}\right]
\end{aligned}
$$

Unknown speed vectors: linear V (U, V, W); angular' $\Omega(\mathrm{P}, \mathrm{Q}, \mathrm{R})$.

Mass terms: total mass(m); moments of inertia - axial /deviational (Jx, Jy, Jz /Jxy, Jxz, Jyz), static moments ( $\mathrm{Sx}, \mathrm{Sy}, \mathrm{Sz})$.

Vector of external loads: forces $F(X, Y, Z)$ and moments $M(L, M, N)$.
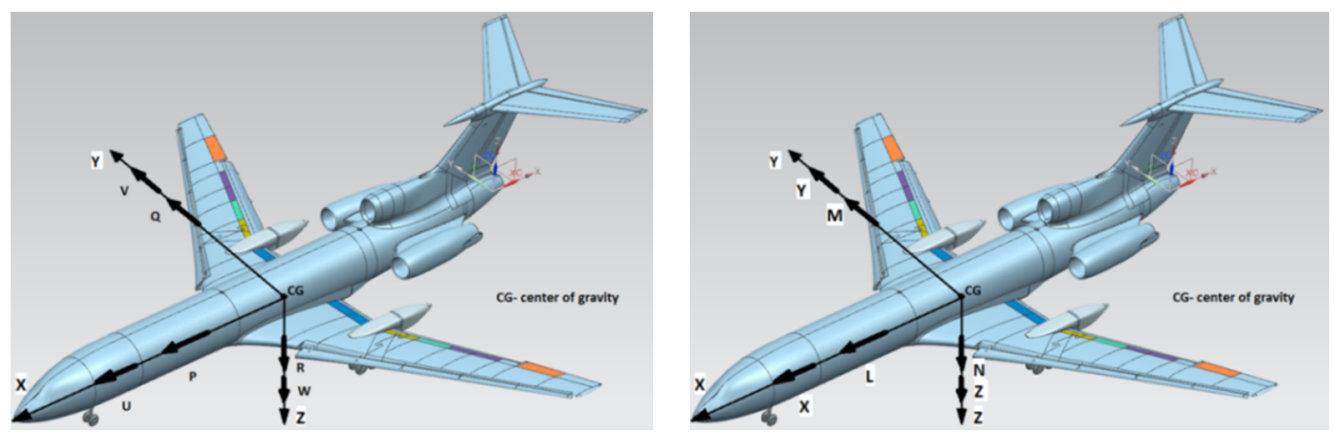

Fig. 4. Vector components of characteristic dynamic qualities:

a) velocity vectors: linear $\mathrm{V} 0(\mathrm{U}, \mathrm{V}, \mathrm{W})$ and angular' $\Omega(\mathrm{P}, \mathrm{Q}, \mathrm{R})$,

b) load vectors: forces $F(X, Y, Z)$ and moments $M(L, M, N)$.

Dynamic motion equation for any force vector $\mathbf{X}$ is the following:

$$
m(\dot{\mathbf{U}}+\mathbf{Q W}-\mathbf{R V})-S_{x}\left(\mathbf{Q}^{2}+\mathbf{R}^{2}\right)-S_{y}(\dot{\mathbf{R}}-\mathbf{P Q})+S_{z}(\dot{\mathbf{Q}}-\mathbf{P R})=\mathbf{X}
$$

Dimensionless form $\mathbf{X}$, after dividing equation (2) by the dynamic term $\left(\rho S v_{0}^{2}\right)$ :

$$
\frac{1}{\rho S v_{0}^{2}}\left[m(\dot{\mathbf{U}}+\mathbf{Q W}-\mathbf{R V})-S_{x}\left(\mathbf{Q}^{2}+\mathbf{R}^{2}\right)-S_{y}(\dot{\mathbf{R}}-\mathbf{P Q})+S_{z}(\dot{\mathbf{Q}}-\mathbf{P R})\right]=\mathbf{X}_{\mathbf{d}}
$$


Right side of equation (2):

$$
\begin{aligned}
& \mathbf{X}=1 / 2 C_{z} \sin \alpha-1 / 2 C_{x} \cos \alpha-\frac{m g}{\rho S v_{0}^{2}} \sin \vartheta+\mathbf{T}_{\mathbf{d}} \cos \varphi_{S} \\
& \text { where } \mathbf{T}_{\mathbf{d}}=\frac{\mathbf{T}}{\rho S V_{0}^{2}} \text { is dimensionless engine trust. }
\end{aligned}
$$

To maintain dynamic similarity, the components of dimensionless equation (3) of the model and the real plane must be equal. The same transformations for next 5 equations can be done. Hence the dynamic similarity scale coefficients are determined.

Basic similarity coefficients are shown in table 1.

\begin{tabular}{|c|c|}
\hline SCALE FACTOR & VALUE (*) \\
\hline Linear dimention & $\mathrm{n}$ \\
\hline Angle of attack & 1 \\
\hline Linear acceleration & 1 \\
\hline Mass & $\mathrm{n}^{\wedge} 3 / \mathrm{k}$ \\
\hline Moment of inertia & $\mathrm{n}^{\wedge} 5 / \mathrm{k}$ \\
\hline Linear velocity & $\mathrm{n}^{\wedge} 1 / 2$ \\
\hline Angular velocity & $1 / \mathrm{n}^{\wedge} 1 / 2$ \\
\hline Time & $\mathrm{n}^{\wedge} 1 / 2$ \\
\hline Density $\quad\left(\mathrm{m} / \rho / 1^{\wedge} 3\right)$ & 1 \\
\hline Freud number $\quad\left(v^{\wedge} 2 / 1 / g\right)$ & 1 \\
\hline Reynolds number & $\mathrm{n}^{\wedge} 1,5 \times \mathrm{v} / \mathrm{v}_{0}$ \\
\hline \multicolumn{2}{|c|}{$\begin{array}{l}\mathrm{k} \text { - air density factor, } \\
\mathrm{k}=\rho \mathrm{h} 1 / \rho \mathrm{h} 2 \\
\mathrm{v}-\mathrm{kinematic} \text { viscosity coefficient; } \\
v_{0} \text { - kinematic viscosity coefficient at sea level } \\
(*) \text { - for flight conditions without the effect of compressibility. }\end{array}$} \\
\hline
\end{tabular}

Table 1. Basic similarity coefficients.

\section{The concept of scaled model of Tu-154M passenger aircraft}

The aim of the project is to test the model of Tu-154M aircraft in transient states of flight and after loss of control by the crew. The following physical features seem to be necessary to keep at recreating the scaled model aircraft:

- free flight conditions,

- remote control link,

- dynamically scaled airframe, 
- $\quad$ similarity of weight distribution and inertia parameters,

- properly rescaled stiffness parameters of model components,

- linear scale factor $\mathrm{n}=1: 14$,

- jet propulsion system.

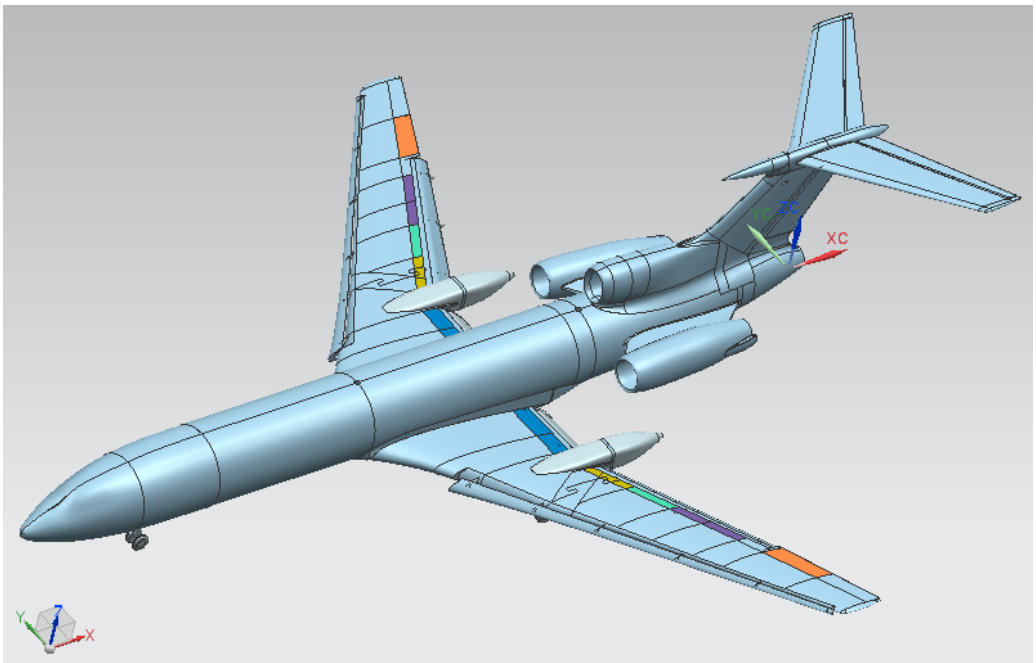

Fig.6. Geometric model of Tu-154M aircraft in landing configuration (NX Siemens).

\section{Estimating scale factors in relation to selected similarity features for Tu-154M model in linear scale 1:14}

Similarity coefficients for Tu-154M in 1:14 scale are shown in table.2. The factors were determined taking into account the following assumptions:

- model and real plane are at the same flight altitude;

- the effect of compressibility was omitted;

- moments of inertia determined for the aircraft mass of $78000 \mathrm{~kg}$ (in landing configuration).

Table 2. Similarity coefficients determined for Tu-154M model in 1:14 scale.

\begin{tabular}{|l|l|l|l|l|}
\hline \multicolumn{1}{|c|}{ Parameter } & \multicolumn{1}{c|}{ Plane } & \multicolumn{1}{c|}{ Unit } & \multicolumn{1}{c|}{ Scale factor } & Model \\
\hline Minimal Mass & 55000 & $\mathrm{~kg}$ & $\mathrm{n}^{\wedge} 3$ & 20.0 \\
\hline Maximum Mass & 102000 & $\mathrm{~kg}$ & $\mathrm{n}^{\wedge} 3$ & 37.2 \\
\hline Max engines thrust & 106000 & $\mathrm{daN}$ & $\mathrm{n}^{\wedge} 3$ & 38.6 \\
\hline Wingspan & 37.6 & $\mathrm{~m}$ & 1 & 2.69 \\
\hline Hull legth & 47.9 & $\mathrm{~m}$ & 1 & 3.42 \\
\hline Reference surface & 201.5 & $\mathrm{~m} \wedge 2$ & $\mathrm{n}^{\wedge} 2$ & 1.03 \\
\hline Velocity, minimum & 65.3 & $\mathrm{~m} / \mathrm{s}$ & $\mathrm{n}^{\wedge} 1 / 2$ & 17.4 \\
\hline Velocity, landing & 80 & $\mathrm{~m} / \mathrm{s}$ & $\mathrm{n}^{\wedge} 1 / 2$ & 21.4 \\
\hline Velocity, maximum & 263.9 & $\mathrm{~m} / \mathrm{s}$ & $\mathrm{n}^{\wedge} 1 / 2$ & 70.5 \\
\hline Moment of inertia Icg x & 2210000 & $\mathrm{kgm}{ }^{\wedge} 2$ & $\mathrm{n}^{\wedge} 5$ & 4.1 \\
\hline Moment of inertia Icg y & 7000000 & $\mathrm{kgm}{ }^{\wedge} 2$ & $\mathrm{n}^{\wedge} 5$ & 13 \\
\hline Moment of inertia Icg $\mathrm{z}$ & 9390000 & $\mathrm{kgm} \wedge 2$ & $\mathrm{n} \wedge^{\wedge} 5$ & 17.5 \\
\hline
\end{tabular}




\section{Application of scaling results to dimensioning the selected structural component of the model}

As example of dimensioning the wing structural elements is presented.

The wing aerodynamic properties are associated with structure rigidity. For accurate results of the model's flight tests, scaling of stiffness and mass distribution of wing is important. The wing model structure in particular is to provide dynamic scaling of mass, mass moments of inertia and geometrical moments of inertia.

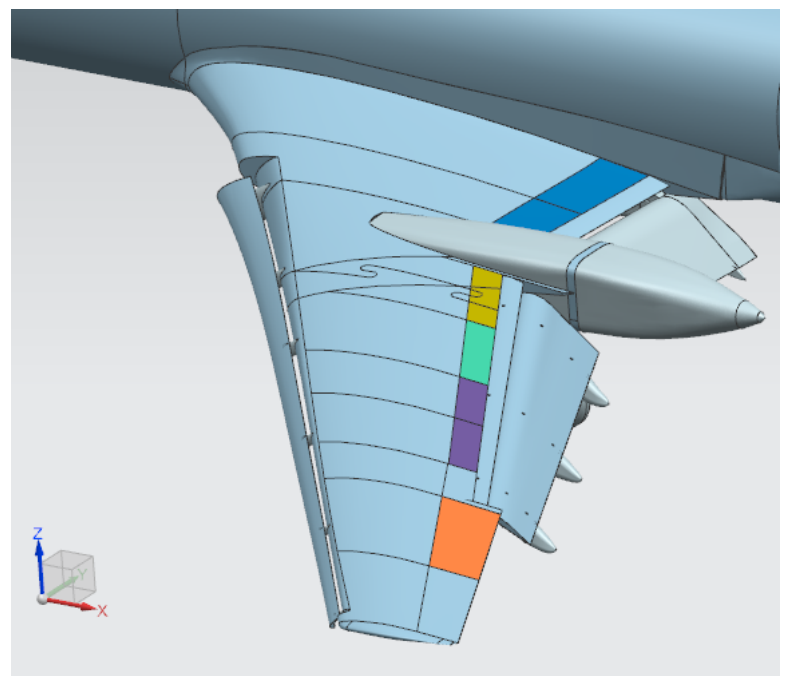

Fig.7. Left wing of TU 154M model. Configuration for start/landing: slots and flaps open.

As example, we show below dynamic scaling of wing stiffness, assuming that both objects are of the same material.

The way of determining geometrical moments of inertia of the real airplane wing based on prepared CAD model was shortly described then.

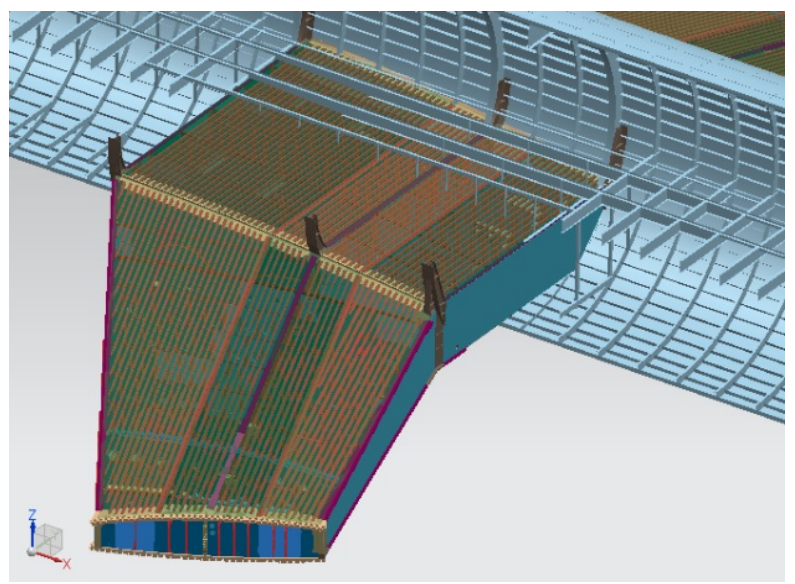

Fig.8. 3D model of centerwing and fuselage structure in 1:1 scale. 


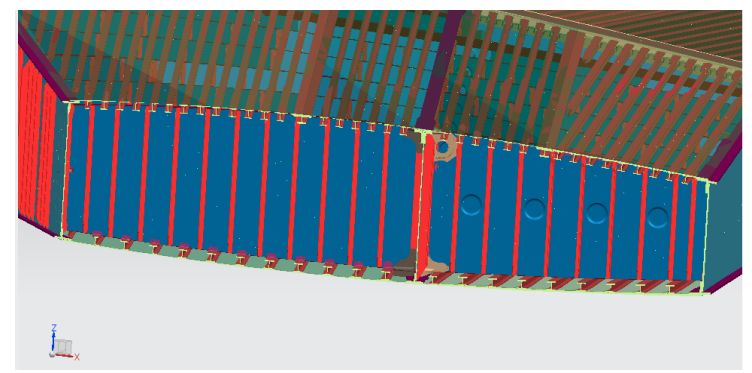

Fig.9. Centerwing caisson structure in 1:1 scale. Cross section view in plane paralell to the ribs.

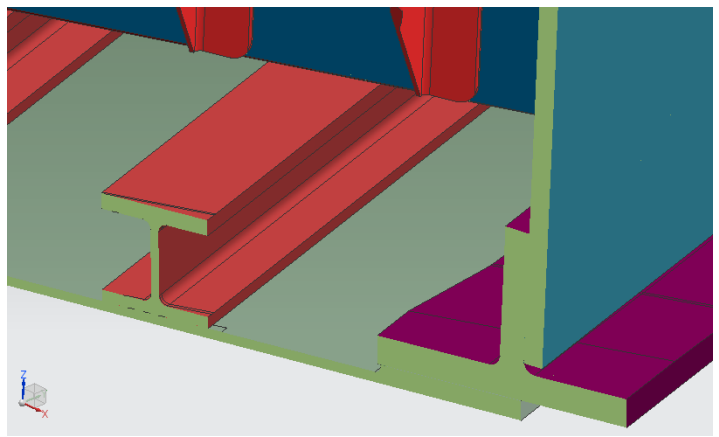

Fig.10. Centerwing caisson structure in 1:1 scale. Bottom skin, stringer and rear spar crossections.

Stiffness scale factors of Centerwing caisson (fig.11).

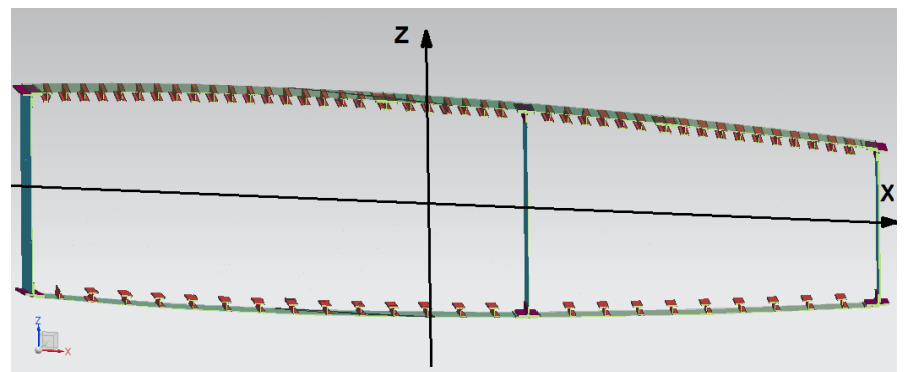

Fig.11. Centerwing caisson structure in 1:1 scale - cross-sectional scheme.

Geometrical moments of inertia for the wing section of the real airplane:

$$
\begin{aligned}
& I_{x}=\sum\left(A_{i} * z_{i} \wedge 2\right) ; \text { where } A_{i}-\text { cross-sectional area of element, }\left[\mathrm{m}^{4}\right] \\
& I_{z}=\sum\left(A_{i} * x_{i} \wedge 2\right) ; \text { where } A_{i}-\text { cross-sectional area of element, }\left[m^{4}\right]
\end{aligned}
$$

Determination of the geometrical moments of inertia of scaled model wing: To get proper geometrical moments of inertia of scaled model, the results of formulas (3) and (4) are multiplied by scale factor:

Linear scale factor $=\mathrm{n}$;

Geometrical moments of inertia scale factor $=n \wedge 4$.

Geometrical moments of inertia for the wing section of model:

Mass moment of inertia about the $\mathrm{x}$-axis of the model $\left(\mathrm{I}_{\mathrm{x}-\mathrm{mod}}\right)$ is as follows: 


$$
\mathrm{I}_{\mathrm{x}-\bmod }=\mathrm{I}_{\mathrm{x}} \times \mathrm{n} \wedge 4
$$

In the similar way the mass moment of inertia about the z-axis of the model $\left(\mathrm{I}_{\mathrm{z}-\mathrm{mod}}\right)$ was calculated:

$$
\mathrm{I}_{\mathrm{z}-\mathrm{mod}}=\mathrm{I}_{\mathrm{z}} \times \mathrm{n}^{\wedge} 4
$$

\section{Conclusions}

As follows from the above, building dynamically scaled aircraft models is not easy and rather complicated process, but anyway it is relatively inexpensive in relevance to manufacturing costs of real aircraft.

Thanks to the dynamic scaled models, the results of tests in-flight can be obtained at the conceptual design stage, which allows significantly to reduce the time and costs of new aircraft development. What is more the dynamic scaled models tests give the oportunity to study the behavior of aircraft in dangerous flight conditions. Increasing the popularity of such research should definitely increase the safety of aviation.

Research with the use of dynamic scaled model of Tu-154M aircraft has been started at Military University of Technology in Warsaw, which will allow in practice to confirm the above theses.

The methods and results described herein comes from research programs granted and financed by the Polish government organizations, namely: Ministry of National Defence and Ministry of Science and Higher Education. The paper was elaborated basing on data taken from the following projects implemented in FMA MUT:

$>$ Project No. 540/2017/DA: Development of technology for the digitizing of external geometry and internal structure of large aircraft for the needs of numerical models creation.

$>$ Statutory research project No. 882/2019: Experimental and numerical research on the development of research technologies in the field of developing an airborne combat system platform.

\section{References}

1. M.V. Cook, Flight Dynamics Principles, Elsevier Ltd, second edition, 468 (2007)

2. Ch. H. Wolowicz, J.S. Bowman, W.P. Gilbert, Similitude Requirements and Scaling Relationships as Applied to Model Testing, NASA Technical Paper 1435, 61 (1979)

3. J.R. Chambers, Modeling Flight: The Role of Dynamically Scaled Free-Flight Models in Support of NASA's Aerospace Programs, NASA SP 2009-575, Washington, first edition, 192 (2010)

4. T.L. Jordan, W.M. Langford, J.s.Hill, Airborne Subscale Transport Aircraft Research Testbed-Aircraft Model Development, NASA Langley Research Center, VA, 23681

5. A.M. Murch, J.V. Foster, Recent NASA Research on Aerodynamic Modeling of PostStall and Spin Dynamics of Large Transport Airplanes (AIAA 2007-463)

6. Z. Goraj, K. Kitmann, R.V. Nitschmann, M. Szender: Design and Integration of Flexi Bird - a low cost sub-scale research aircraft for safety and environmental issues, $27^{\text {th }}$ International Congress of Aeronautical Sciences, Nice, France, (2010)

7. M.Ch.Y. Niu, Composite Airframe Structures, Practical design information and data, Conmilit Press Ltd, 663 (1992)

8. D.P. Raymer, Aircraft Design: A conceptual approach, fifth edition, 1043 (2012)

9. C. Galiński, Wybrane Zagadnienia Projektowania Samolotów, Biblioteka Naukowa Instytutu Lotnictwa 44, Warsaw, Poland, 396 (2016) 